\title{
A Fast Test System to Evaluate the Physical Protection Potential of Textiles against Blood-Sucking Insects
}

\author{
Timo Hammer, Anja Gerhardts, Dirk Hoefer \\ Hohenstein Institute, Boennigheim, Germany \\ Email: ^d.hoefer@hohenstein.de
}

How to cite this paper: Hammer, T., Gerhardts, A. and Hoefer, D. (2018) A Fast Test System to Evaluate the Physical Protection Potential of Textiles against BloodSucking Insects. Journal of Textile Science and Technology, 4, 79-84.

https://doi.org/10.4236/jtst.2018.43005

Received: May 24, 2018

Accepted: July 30, 2018

Published: August 3, 2018

Copyright (c) 2018 by authors and Scientific Research Publishing Inc. This work is licensed under the Creative Commons Attribution International License (CC BY 4.0).

http://creativecommons.org/licenses/by/4.0/

\begin{abstract}
Blood-sucking insects can cause severe health damage in humans and animals for example by causing allergic reactions or by the propagation of vector-borne diseases such as malaria. Textiles are widely used for insect protection with bednets, curtains or outdoor clothing. The main approach is functionalization of the textiles with insect repellents like DEET or insecticides like permethrin. Instead of or in addition to these chemical measures the mechanical protection potential of the fabric itself has to be considered for preventing insect bites and stings effectively. Densely woven fabrics or spacer fabrics can serve as a chemical-free protection system. To compare the physical protection potential of different textiles against the mouthparts and stings of blood-sucking insects, we developed an easy and reliable test system which can be used in textile research institutes and companies. The system is mobile and can also be applied on wet textiles. We here describe the construction and validation of our new test system.
\end{abstract}

\section{Keywords}

Malaria, Mouthpart, Outdoor, Spacer Fabric, Vector-Protection

\section{Introduction}

Textiles can provide an excellent protection from insect attacks to humans and animals and are therefore widely used for this purpose. Blood-sucking insects are a considerable threat for human and animal health in respect of the propagation of pathogens, pain, allergic reactions or inflammation. Vector-borne diseases are caused by microorganisms or protozoa propagated by such insects. The most important parasitic infection for humans is malaria, causing more than 1 million deaths per year [1]. The malaria vector, Anopheles sp, is mainly present 
in the southern hemisphere, but due to global warming, the insect's habitat currently extends northward. Other insects account for acute allergic reactions, which can also end lethal for the suffering person. Beside humans, there are also several negative effects of blood-sucking insects on animals. It could be shown for example, that blood-sucking Diptera such as horseflies and mosquitoes, can cause reduced milking qualities of dairy cattle [2]. In addition, in Europe, many horses suffer from summer eczema, a problematic dermatitis resulting from allergic reactions to insect saliva [3]. Another problem is the conduction of equine infectious anemia virus (EIAV) or anaplasmosis by horseflies (Tabanidae) [4] [5].

Two major strategies can be used for effective insect protection with textiles: repellent- or insecticide-treated fabrics for chemical protection and physical protection with the textile representing a mechanical barrier for the insects' mouthparts and stings. Many studies show the efficacy of chemical protection with repellents such as DEET or insecticides like permethrin [6] [7] [8] [9]. As more and more consumers refuse the use of insecticides or repellents in clothes, especially for children, new products have to be developed which effectively protect from insects due to their physical properties. For this purpose, densely woven cloth or innovative spacer fabrics could be used. Spacer fabrics may serve as an efficient physical barrier due to the distance between their surface and the skin or due to their material composition. The important protection parameters are thickness of the material and its potential to prevent penetration of the insects' mouthparts. By now there is no reliable test system to evaluate the mechanical barrier function of textiles against insects' mouthparts. The relevant insects are of different size and show a different mouthpart anatomy. The main vectors propagating human and animal diseases are Anopheles sp, Aedes sp, Culex sp, Stomoxys sp, Culicoides sp, Simulium sp, Tabanus sp and Haematopotasp.

In order to evaluate the physical barrier function of textiles or other laminar materials against blood-sucking insects, usually complex experimental setups with living insects have to be conducted. As these experiments are timeconsuming and expensive, an easy test system for the pre-screening of different materials for their mechanical barrier function is needed. Here we describe an easy, cheap and reliable system for testing penetration of textiles by insect mouthparts.

\section{Materials and Methods}

The test device is shown in Figure 1. It consists of a fixing plate (Figure 1(A1)) and an insect mouthpart simulating penetration device (Figure 1(B1)). The fixing plate was made of a medium-density fibreboard (MDF), $130 \times 110 \times 17 \mathrm{~mm}$. On one side of the board an area of $45 \times 55 \mathrm{~mm}$ was milled to create a depression with $8 \mathrm{~mm}$ in depth. The depression was filled with a total of 4 trimmed plates of dental wax of $2 \mathrm{~mm}$ thickness each (Morsa, Germany) (Figure 1(A1)). 
On each corner of the device a wing screw was installed to fix the test material (Figure 1(A2)).

For the construction of the penetration device different acupuncture and hollow needles with diameters between 0.12 and $1.1 \mathrm{~mm}$ were used to represent a broad variety of insect mouthparts (acupuncture needles from Asia-Med, Germany; hollow needles from B. Braun, Germany). 24 needles were arranged with constant distances through the holes of a perforated plastic plate $(70 \times 70 \mathrm{~mm})$ and fixed with a paraffin/polyethene sheet (Parafilm "M", American National Can Company, USA). The whole plate was put on top of an empty plastic container $(65 \times 65 \mathrm{~mm})$ with the needle tips up. Subsequently, the container was filled with hardener-activated liquid 2-component polyester resin (Aura, Germany) in order to embed the needle grids. Prior to polymerization of the resin, the needles were adjusted with forceps to their final position. After $24 \mathrm{~h}$ the resin was polymerized. The resulting penetration device was a compact block with 24 needle tips on its top differing in diameter and length (Figure 1(B1) and Figure 1(B2)). The resulting test pattern is shown in Table 1(a).

Various textiles were used to evaluate the reliability of the test system. As a control, woven fabric or $100 \% \mathrm{CO}$ with $150 \mathrm{~g} / \mathrm{m}^{2}$ and $0.26 \mathrm{~mm}$ thickness was used. All materials were tested twice. First, they were conditioned at $20^{\circ} \mathrm{C}$ and a relative humidity of $50 \%$ prior to testing. For the second testing, they were previously conditioned at $36^{\circ} \mathrm{C}$ and $60 \%$ relative humidity.
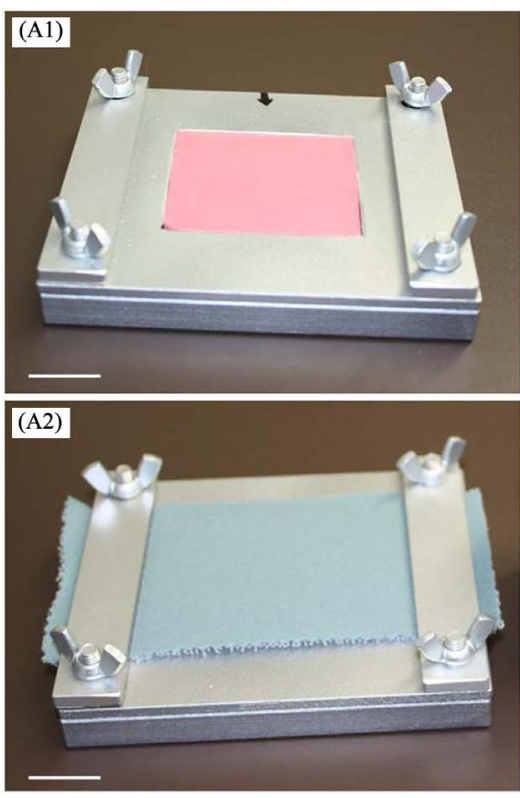
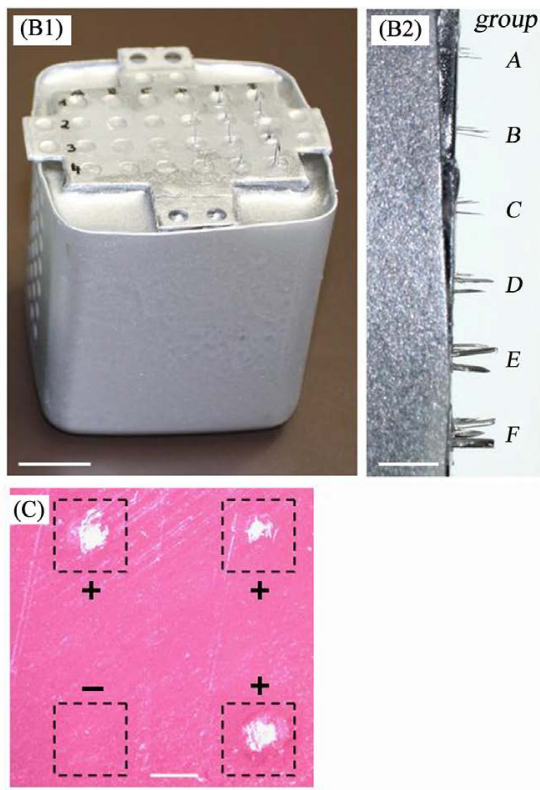

Figure 1. Test system for the mechanical barrier function of textiles against insect mouthparts. (A1): Fixing device filled with dental wax. Scale $=25 \mathrm{~mm}$; (A2): Textile mounted on fixing device. Scale $=25 \mathrm{~mm}$; (B1): Penetration device with 24 needle tips protruding from upper side. Scale $=20 \mathrm{~m}$; (B2): Detail upper side; needle tips representing the insects' mouthparts. Please note different mouthpart's group A-F (details in Table 1). Scale $=4 \mathrm{~mm}$; (C): Dental wax contrasted with magnesium oxide. Areas of textile penetration appear white $(+)$, areas where no penetration occurred remain red (-). Scale $=1 \mathrm{~mm}$. 
Table 1. (a): Test pattern of penetrating device (diameter/length of the needle in $\mathrm{mm}$ ) with each table cell representing a distinct insect's mouthpart anatomy. Please compare mouthpart's group A-F with Figure 1, section B2; (b): Test pattern of penetrating device indicating the observed penetration of fabric samples 1,2 and/or 3; $1: 2 \mathrm{~mm}$ spacer fabric, 2: $2.5 \mathrm{~mm}$ spacer fabric, $3: 3 \mathrm{~mm}$ spacer fabric.

(a)

\begin{tabular}{ccccccc}
\hline & $\mathrm{A}$ & $\mathrm{B}$ & $\mathrm{C}$ & $\mathrm{D}$ & $\mathrm{E}$ & $\mathrm{F}$ \\
\hline $\mathbf{4}$ & $0.16 / 1$ & $0.16 / 2$ & $0.20 / 3$ & $0.40 / 3.5$ & $0.70 / 4$ & $1.10 / 5$ \\
$\mathbf{3}$ & $0.14 / 2$ & $0.14 / 3$ & $0.20 / 2$ & $0.40 / 5$ & $0.60 / 6$ & $1.10 / 4$ \\
$\mathbf{2}$ & $0.12 / 3$ & $0.14 / 4$ & $0.20 / 1$ & $0.30 / 3$ & $0.60 / 3$ & $0.80 / 5$ \\
$\mathbf{1}$ & $0.12 / 1$ & $0.12 / 4$ & $0.16 / 3$ & $0.30 / 2$ & $0.40 / 4$ & $0.80 / 3$ \\
\hline
\end{tabular}

(b)

\begin{tabular}{ccccccc}
\hline & A & B & C & D & E & F \\
\hline 4 & - & - & - & 1 & $1 / 2$ & $1 / 2 / 3$ \\
3 & - & 1 & - & $1 / 2 / 3$ & $1 / 2 / 3$ & $1 / 2$ \\
2 & 1 & 1 & - & - & - & $1 / 2 / 3$ \\
1 & - & 1 & 1 & - & $1 / 2 / 3$ & - \\
\hline
\end{tabular}

From each material pieces of $200 \times 80 \mathrm{~mm}$ were excised and fixed on the fixing plate. Subsequently, the penetration device was applied upside-down on the textile for 2 minutes with a distinct force $(3.43 \mathrm{~N})$, defined by the weight of the device $(350 \mathrm{~g})$. After the removal of the device and the textile samples, the remaining dental wax was powdered with magnesium oxide to contrast the holes (Figure $1(C)$ ). The number and positions of the holes in the wax were determined microscopically.

\section{Results and Discussion}

We obtained constant results when applying the test system on different probes of the same material. This shows the reliability of this simple testing device. The needle tips gently glided into the dental wax, which therefore proved to be a suitable material for the penetration experiments. For a better contrast and an evaluation of the extent of penetration, the dental wax sprinkled after the penetration process by a layer of white magnesium oxide powder. Moreover, the layered build-up of the four dental wax plates in the fixing plate enables an in-depth examination of penetration.

As expected, the physical barrier function of the textile samples differed depending on their thickness and composition of the material. A standard cotton cloth used as a negative control was penetrated by all surrogate mouthparts, indicating that standard cotton textiles cannot provide a sufficient protection from insect bites. On the other hand, a spacer fabric of $2 \mathrm{~mm}$ thickness was able to provide a basic protection against smaller insects. In these experiments, penetration could be detected on spots A2, B1, B2, B3, C1, D3, D4, E1, E3, E4 and F2-4 
(compare Table 1(b)). A $2.5 \mathrm{~mm}$ thick polyester spacer fabric containing a polyurethane laminar membrane used for breathable outdoor clothing displayed a significant barrier function against small and mid-size insects. In these experiments, penetration could be detected on spots D3, E1, E3, E4 and F2-4. In contrast to this, a $3 \mathrm{~mm}$ polyester spacer fabric without polyurethane membrane was penetrated on spots D3, E1, E3, F2 and F4, thus providing a good barrier function against most blood-sucking insects. The results clearly show that fabrics are easier penetrated by needles which have lower diameters and higher length, respectively. Therefore, insect's mouthparts such as those represented in group C (see Figure 1, section B2 and Table 1(a)), i.e. longer mouthparts with lower diameter, are most likely to cause stitches and bites when the skin is not fully protected by functional fabrics. In this respect, it is noteworthy, that a common horsefly has mouthparts of about $1.1 \mathrm{~mm}$ length with a diameter of $50 \mu \mathrm{m}$. Hence, spacer fabrics are most likely to be the most efficient protection garment due to their structural height. However, although in our experiments we did not evaluate the degree of penetration, it would easily be possible to assess this endpoint by common image-analysis system due to the contrasting of the dental wax with magnesium oxide.

The $3 \mathrm{~mm}$ polyester spacer fabric was effectively used as fly protections in field test for the protection of horses, when these were out at the corral in summer time (data not shown). Especially, the covers were able to protect the horses against biting midges and blackflies, which are very common in Germany and are known to cause summer eczemas on horses.

It is expected that different blood-sucking insects will bite or sting with varying force, which is not considered in this model. But even if the force applied by the weight of the device part B might not be similar to that of an actual mosquito, the test design is suitable for a fast and inexpensive pre-screening of fabric samples. The advantage of the application of a constant pressure is the comparability between individual results for diverse textiles. The fixed positioning of the needles at an angle of $90^{\circ}$ to the fabric, unlike different penetration angles of various mosquitoes, describes a worst case scenario as this represents the shortest distance through the textile.

\section{Conclusion}

In conclusion, the fast, cost-effective and reliable test system developed in our lab can be used to classify the physical barrier function of laminar or spacer materials prior to tests with living insects. In this respect, a pre-screening of materials for their protective potential can be performed to avoid the more expensive and time-consuming insect experiments. To our knowledge, there is no other insect-free test system available, which has the potential to be standardised as a lab method. This is especially important for projects with many fabric samples or if the tests with living insects have to be reduced to a certain amount due to economic or logistic reasons. 


\section{Conflicts of Interest}

The authors declare no conflicts of interest regarding the publication of this paper.

\section{References}

[1] Greenwood, B.M., Bojang, K., Whitty, C.J. and Targett, G. (2005) Malaria. Lancet, 9469, 1487-1498. https://doi.org/10.1016/S0140-6736(05)66420-3

[2] Minar, J., Riha, J. and Lamatova, Z. (1979) Losses in Milking Qualities of Dairy Cattle Caused by Mosquitoes and Horseflies and Reduction of Such Losses Due to Use of Diethyltoluamide Repellent. Folia Parasitologica (Praha), 26, 285-288.

[3] Hallamaa, R.E. (2009) Characteristics of Equine Summer Eczema with Emphasis on Differences between Finnhorses and Icelandic Horses in a 11-Year Study. Acta Veterinaria Scandinavica, 51, 29. https://doi.org/10.1186/1751-0147-51-29

[4] Hawkins, J.A., Adams, W.V., Wilson, B.H., Issel, C.J. and Roth, E.E. (1976) Transmission of Equine Infectious Anemia Virus by Tabanus fuscicostatus. Journal of the American Veterinary Medical Association, 168, 63-64.

[5] Hawkins, J.A., Love, J.N. and Hidalgo, R.J. (1982) Mechanical Transmission of Anaplasmosis by Tabanids (Diptera: Tabanidae). American Journal of Veterinary Research, 43, 732-734.

[6] Deparis, X., Frere, B., Lamizana, M., N'Guessan, R., Leroux, F., Lefevre, P., Finot, L., Hougard, J.M., Carnevale, P., Gillet, P. and Baudon, D. (2004) Efficacy of Permethrin-Treated Uniforms in Combination with Deet Topical Repellent for Protection of French Military Troops in Cote d'Ivoire. Journal of Medical Entomology, 41, 914-921. https://doi.org/10.1603/0022-2585-41.5.914

[7] Fei, B. and Xin, J.H. (2007) N, N-diethyl-m-toluamide-containing Microcapsules for Bio-Cloth Finishing. The American Journal of Tropical Medicine and Hygiene, 77, 52-57.

[8] Hebeish, A., Hamdy, A., El-Sawy, S.M. and Abdel-Mohdy, F.A. (2010) Preparation of Durable Insect Repellent Cotton Fabric through Treatment with a Finishing Formulation Containing Cypermethrin. Journal of the Textile Institute, 101, 627-634. https://doi.org/10.1080/00405000902732859

[9] Abdel-Mohdy, F.A., Fouda, M.M.G., Rehan, M.F. and Ali, A.S. (2009) Repellency of Controlled-Release Treated-Cotton Fabrics Based on Permethrin and Bioallethrin against Mosquitoes. Journal of the Textile Institute, 100, 695-701.

https://doi.org/10.1080/00405000802170275 